\title{
Similarity considerations on wall heat losses in internal combustion engines
}

P Eilts, Dr-Ing

Institut für Kolbenmaschinen, Universität Hannover, Hannover, Germany

The drop in wall heat losses with increasing engine size is shown not to be due to the decreasing surface-volume ratio, because this influence is compensated by the engine speed, which also drops. Instead, the heat-transfer coefficient decreases as the cylinder bore becomes larger. The dependence of the heat-transfer coefficient on engine size is explained using Reynolds' analogy.

This dependence can be used to determine approximately changes in wall heat losses resulting from differences in engine size and the subsequent effects on indicated efficiency. It is found that only a minor part of the differences in efficiency between small and large engines is due to size-dependent changes in wall heat losses.

\section{NOTATION}

\section{$A \quad$ area $\left(\mathrm{m}^{2}\right)$ \\ B cylinder bore (m)}

bsfc brake specific fuel consumption $(\mathrm{kg} / \mathrm{kW} \mathrm{h})$

$h$ specific enthalpy $(\mathrm{J} / \mathrm{kg})$

$k$ thermal conductivity $(\mathrm{W} / \mathrm{m} \mathrm{K})$

$l$ connecting rod length $(\mathrm{m})$

$L \quad$ piston stroke (m)

m mass (kg)

$n \quad$ engine speed $\left(s^{-1}\right)$

$\mathrm{Nu}$ Nusselt number

$p \quad$ cylinder pressure $(\mathrm{Pa})$

Pr Prandtl number

$Q$ quantity of heat $(\mathrm{J})$

$r_{c} \quad$ compression ratio

$\boldsymbol{R}$ crank radius (m)

Re Reynolds number

$S_{\mathrm{p}} \quad$ mean piston speed $(\mathrm{m} / \mathrm{s})$

$t$ time (s)

$T$ temperature (K)

$u \quad$ specific internal energy of cylinder contents $(\mathrm{J} / \mathrm{kg})$

$U$ internal energy of cylinder contents $(J)$

$v \quad$ local velocity $(\mathrm{m} / \mathrm{s})$

$V \quad$ cylinder volume $\left(\mathrm{m}^{3}\right)$

$w \quad$ velocity averaged over cross-section $(\mathrm{m} / \mathrm{s})$

$W \quad$ work done by the piston $(J)$

$y$ distance from the wall (m)

$\alpha \quad$ heat-transfer coefficient $\left(W / \mathrm{m}^{2} \mathrm{~K}\right)$

$\zeta \quad$ friction coefficient

$\eta_{1} \quad$ indicated efficiency

$\eta_{m} \quad$ mechanical efficiency

$\eta_{\text {th }}$ thermal efficiency

$\Theta \quad$ crank angle (rad)

$v \quad$ kinematic viscosity $\left(\mathrm{m}^{2} / \mathrm{s}\right)$

$\phi \quad$ equivalence ratio

\section{Subscripts and superscripts \\ 0 reference condition \\ c gas in the cylinder \\ e exhaust \\ f fuel}

The MS was received on 3 May 1990 and was accepted for publication on 8 August 1990.

A02190@ IMechE 1991

$\begin{array}{ll}\text { i } & \text { into cylinder } \\ \text { o } & \text { out of cylinder } \\ \text { v } & \text { valve } \\ \text { w } & \text { cylinder wall } \\ \text {, approximate calculation }\end{array}$

\section{INTRODUCTION}

It is well known that large internal combustion engines have higher efficiencies than small ones. This phenomenon is often attributed to their smaller wall heat losses, which are said to be due to the surface-volume ratio of the cylinder becoming smaller with increasing engine size. A similar consideration of the working cycle shows that this is not the reason. The consequences of this finding shall be discussed.

\section{SIMILARITY CONSIDERATION OF THE WORKING CYCLE}

The system considered is shown in Fig. 1. The basis for the derivation is the conservation of energy, applied to the cylinder contents:

$$
\frac{\mathrm{d} U}{\mathrm{~d} \Theta}=h_{\mathrm{i}} \frac{\mathrm{d} m_{\mathrm{i}}}{\mathrm{d} \Theta}-h_{\mathrm{o}} \frac{\mathrm{d} m_{\mathrm{o}}}{\mathrm{d} \Theta}+\frac{\mathrm{d} W}{\mathrm{~d} \Theta}+\frac{\mathrm{d} Q_{\mathrm{w}}}{\mathrm{d} \Theta}+\frac{\mathrm{d} Q_{\mathrm{f}}}{\mathrm{d} \Theta}
$$

The derivative of the internal energy can be written as

$$
\frac{\mathrm{d} U}{\mathrm{~d} \Theta}=\frac{\mathrm{d}}{\mathrm{d} \Theta}\left(m_{\mathrm{c}} u\right)
$$

where

$$
\frac{\mathrm{d} u}{\mathrm{~d} \Theta}=\frac{\partial u}{\partial T_{\mathrm{c}}} \frac{\mathrm{d} T_{\mathrm{c}}}{\mathrm{d} \Theta}+\frac{\partial u}{\partial p} \frac{\mathrm{d} p}{\mathrm{~d} \Theta}+\frac{\partial u}{\partial \phi} \frac{\mathrm{d} \phi}{\mathrm{d} \Theta}
$$

and the derivative of the cylinder mass is

$$
\frac{\mathrm{d} m_{\mathrm{c}}}{\mathrm{d} \Theta}=\frac{\mathrm{d} m_{\mathrm{i}}}{\mathrm{d} \Theta}-\frac{\mathrm{d} m_{\mathrm{o}}}{\mathrm{d} \Theta}
$$

Mass fluxes flowing in and out of the cylinder (subscripts $i$ and o) include gas exchange, leakages and fuel supply. 


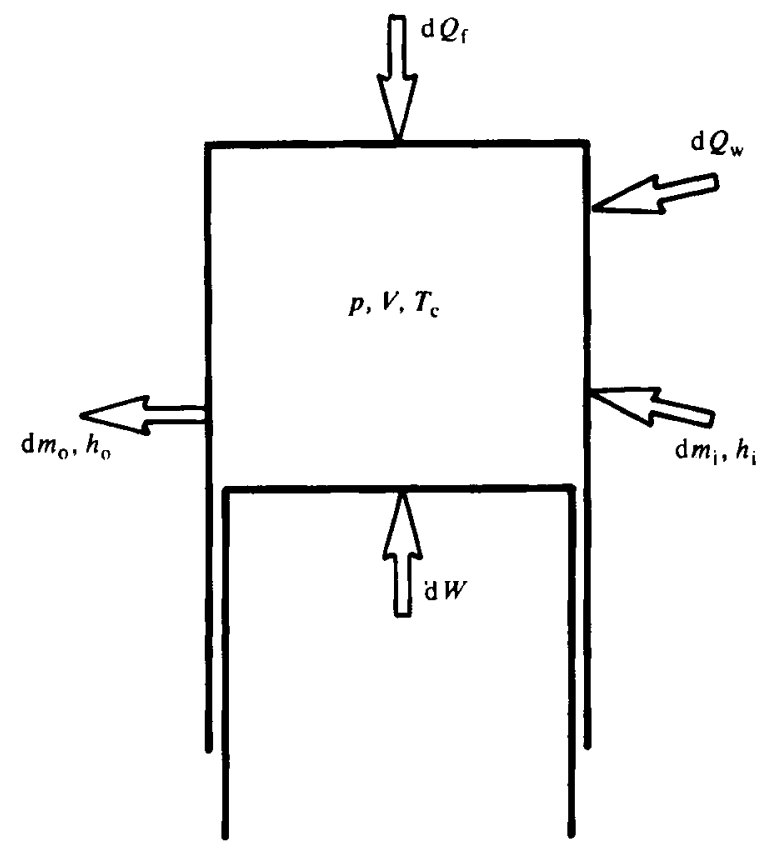

Fig. 1 The system considered

Work performed by the piston is written as

$$
\frac{d W}{d \Theta}=-p \frac{d V}{d \Theta}
$$

and heat transferred to the gas is

$$
\frac{\mathrm{d} Q_{\mathrm{w}}}{\mathrm{d} \Theta}=\alpha A_{\mathrm{w}}\left(T_{\mathrm{w}}-T_{\mathrm{c}}\right) \frac{\mathrm{d} t}{\mathrm{~d} \Theta}
$$

Introducing equations (2) to (6) in equation (1) and solving for $d T_{c} / d \Theta$, we get

$$
\begin{aligned}
\frac{\mathrm{d} T_{\mathrm{c}}}{\mathrm{d} \Theta}= & \frac{1}{\partial u / \partial T_{\mathrm{c}}}\left\{\left(h_{\mathrm{i}}-u\right) \frac{1}{m_{\mathrm{c}}} \frac{\mathrm{d} m_{\mathrm{i}}}{\mathrm{d} \Theta}\right. \\
& -\left(h_{\mathrm{o}}-u\right) \frac{1}{m_{\mathrm{c}}} \frac{\mathrm{d}_{m_{\mathrm{o}}}}{\mathrm{d} \Theta}-p \frac{1}{m_{\mathrm{c}}} \frac{\mathrm{d} V}{\mathrm{~d} \Theta} \\
& +\alpha\left(T_{\mathrm{w}}-T_{\mathrm{c}}\right) \frac{A_{\mathrm{w}}}{m_{\mathrm{c}}} \frac{\mathrm{d} t}{\mathrm{~d} \Theta} \\
& \left.+\frac{1}{m_{\mathrm{c}}} \frac{\mathrm{d} Q_{\mathrm{f}}}{\mathrm{d} \Theta}-\frac{\partial u}{\partial p} \frac{\mathrm{d} p}{\mathrm{~d} \Theta}-\frac{\partial u}{\partial \phi} \frac{\mathrm{d} \phi}{\mathrm{d} \Theta}\right\}
\end{aligned}
$$

Further, it will be worked out under which conditions the histories of pressure and temperature are independent of engine size. For this purpose they are taken to be size independent for the time being and the conditions necessary to keep equation (7) satisfied are evaluated. In addition, geometrical and mechanical similarity (1) is assumed. This means

$$
\begin{aligned}
\frac{L}{B} & =\text { constant } \\
\frac{l}{R} & =\text { constant } \\
S_{\mathrm{p}} & =\text { constant } \\
r_{\mathrm{c}} & =\text { constant }
\end{aligned}
$$

These conditions lead to the following dependencies on engine size:

$$
\begin{aligned}
& A_{\mathrm{w}} \propto B^{2} \\
& A_{\mathrm{v}} \propto B^{2} \\
& V \propto B^{3} \\
& \frac{\mathrm{d} V}{\mathrm{~d} \Theta} \propto B^{3}
\end{aligned}
$$

Because pressure and temperature are assumed to be size independent it follows that

$$
m_{\mathrm{c}} \propto V \propto B^{3}
$$

The constancy of the mean piston speed leads to

$$
\frac{\mathrm{d} t}{\mathrm{~d} \Theta} \propto \frac{1}{n} \propto B
$$

The pressures and temperatures of the gas behind the charge exchange valves or ports and the flow coefficients are also assumed to be size independent. Thus we obtain

$$
\frac{\mathrm{d} m_{\mathrm{i} / \mathrm{o}}}{\mathrm{d} \Theta} \propto A_{\mathrm{v}} \frac{\mathrm{d} t}{\mathrm{~d} \Theta} \propto B^{3}
$$

This is also assumed to be the case for the leakages.

The fuel is assumed to be unchanged and with a sizeindependent rate of heat release it can be written as

$$
\frac{\mathrm{d} Q_{\mathrm{r}}}{\mathrm{d} \Theta} \propto \frac{\mathrm{d} m_{\mathrm{f}}}{\mathrm{d} \Theta} \propto m_{\mathrm{c}} \propto B^{3}
$$

The size-independent rate of heat release means that the equivalence ratio of the gas in the cylinder also does not depend on engine size. The same is valid for the properties of the working fluid. Finally, the wall temperatures are assumed to be size independent.

With this and equations (12) to (19), nearly all terms in equation (7) become size independent. The influence of the surface-volume ratio (represented by the surfacemass ratio here) in the term for heat transfer is eliminated by the influence of speed. The only quantity not considered up to now is the heat-transfer coefficient. If it also was size independent, equation (7) would be satisfied completely for all cylinder bores; that is pressure and temperature in the cylinder would be size independent.

\section{DEPENDENCE OF THE HEAT-TRANSFER COEFFICIENT ON ENGINE SIZE}

Experience shows that the wall heat losses depend on engine size. Because the surface-volume ratio has been found not to be responsible, this influence must therefore result from the dependence of the heat-transfer coefficient on the dimensions of the engine.

A widely used formula for the spatially averaged heat-transfer coefficient was proposed by Woschni $(2,3)$. It is based on the similarity theory of convective heat transfer. Woschni (3) compares heat losses calculated using his formula with experimental results of his own and from other authors. He achieves good agreement. The range of bore diameters investigated is 100 $1000 \mathrm{~mm}$. Woschni starts from an equation for turbu- 
lent heat transfer in a pipe by Hausen:

$$
N u=0.024\left\{1+\left(\frac{B}{L}\right)^{2 / 3}\right\}(R e)^{0.786}(\operatorname{Pr})^{0.45}
$$

With $N u=\alpha B / k$ and $R e=w B / v$ we get

$$
\alpha \propto B^{-0.214}
$$

for $B / L=$ constant, $w=$ constant and constant fluid properties. The exponent was verified and rounded to 0.2 by Woschni (3). Therefore this relation is the reason for the lower heat losses with rising engine size.

\section{REASON FOR THE DEPENDENCE OF THE HEAT-TRANSFER COEFFICIENT ON ENGINE SIZE}

To explain the dependence of the heat-transfer coefficient on engine size, the analogy of momentum and heat transfer found by Reynolds (4) can be used. This shows that the radial profiles of temperature and velocity in a pipe are similar. Thus the velocity profile can be used to consider heat transfer. The gradients of temperature and velocity are relevant for the heat and momentum flux densities between the wall and gas respectively. From the data given by Prandtl (5) it can be derived that close to the wall:

$$
\frac{\mathrm{d} u}{\mathrm{~d} y}=\frac{\zeta w^{2}}{8 v}
$$

and in some distance to the wall:

$$
\frac{\mathrm{d} u}{\mathrm{~d} y}=0.884 \frac{w \zeta^{1 / 2}}{y}
$$

It can be seen that the gradient, and with it the momentum or heat flux density, decreases because the friction coefficient falls with increasing diameter and therefore increasing Reynolds number, assuming constant velocity and fluid properties.

\section{THE EFFECT OF ENGINE SIZE ON WALL HEAT LOSSES AND EFFICIENCY}

Cycle simulations were performed to calculate the effects of engine size under the conditions of similarity described above. It was necessary to use calculations here because data meeting the conditions of similarity and covering a sufficiently wide range of sizes were not available and it would be difficult to obtain them experimentally. The program used is based on the energy and mass conservation equations (1) and (4). Heat release is calculated via a Vibe function (6). For heat transfer to the walls Woschni's equation is used. Only the high-pressure part of the cycle is considered, because the main part of the heat losses occurs there. The conditions at the beginning of compression are calculated with the formula given by Zapf (7).

A medium-speed diesel engine with a bore of $330 \mathrm{~mm}$ and a rated speed of $750 \mathrm{r} / \mathrm{min}$ was used as a basis for the comparison. This reference condition is denoted with subscript 0 . Figure 2 shows the wall heat losses as a function of cylinder bore. The bore diameters investigated cover the range from passenger car engines to low speed two-stroke engines. As expected, the losses decrease with increasing bore.

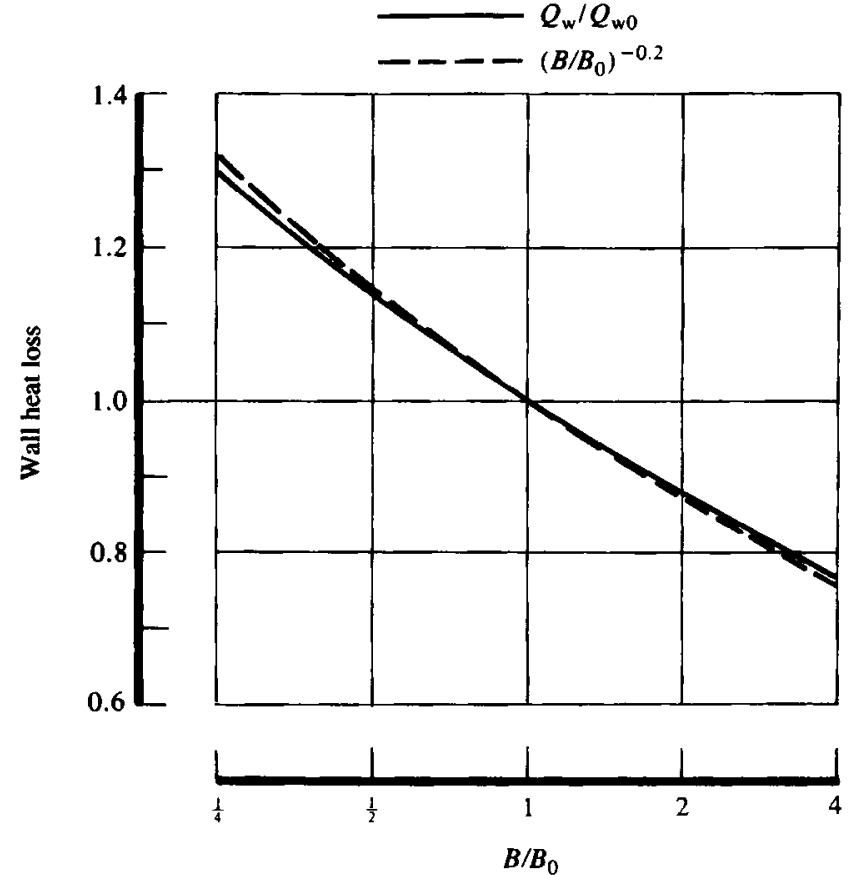

Fig. 2 Influence of engine size on wall heat losses

Further, the function $\left(B / B_{0}\right)^{-0.2}$ is plotted into the same diagram. The two curves are close to each other. The change in heat losses is slightly overpredicted by $\left(B / B_{0}\right)^{-0.2}$, because the gas temperature rises due to the reduced heat-transfer coefficient and so the heat flux increases again.

If the wall heat, the indicated work and the exhaust heat are known for the reference engine and if the relation of indicated work to exhaust heat is assumed to be size independent, the dependence of the indicated efficiency on engine size can be calculated approximately by

$$
\left(\frac{\eta_{\mathrm{i}}}{\eta_{\mathrm{i} 0}}\right)^{\prime}=\frac{1-\left(Q_{\mathrm{wo}} / Q_{\mathrm{fo}}\right)\left(B / B_{0}\right)^{-0.2}}{\eta_{\mathrm{io}}+Q_{\mathrm{co}} / Q_{\mathrm{fo}}}
$$

The superscript ' denotes the approximative calculation. In Fig. 3 the dependencies of the indicated efficiency on cylinder bore calculated using the simulation program and equation (24) are plotted. The latter overpredicts the effect of engine size. This is due to the fact that with a larger bore the exhaust heat rises more than the indicated work.

Fuel consumption data given by a maker of large low-speed two-stroke engines (8) were used for comparison with equation (24). The values for $\left(\eta_{\mathrm{th}} / \boldsymbol{\eta}_{\text {tho }}\right)$ calculated from the given bsfc figures are plotted versus cylinder bore in Fig. 4 , together with $\left(\eta_{i} / \eta_{i 0}\right)^{\prime}$ from equation (24). The reference engine was chosen to be the one with the largest bore. For the calculation of $\eta_{\mathrm{i} 0}$ and $Q_{\mathrm{e} 0}$, $Q_{\mathrm{wo}} / Q_{\mathrm{ro}}$ was assumed as 0.07 and $\eta_{\mathrm{m}}$ as 0.93 . These assumptions are not critical. Equation (24), which has been found above to overpredict the influence of engine size under the conditions of similarity, clearly underpredicts this influence here.

Even in this case, where one would assume similarity to be given, the differences in wall heat losses caused by the dependence of the heat-transfer coefficient on engine size only represent a relatively small part of the total difference in efficiency. The rest may be found in lower 


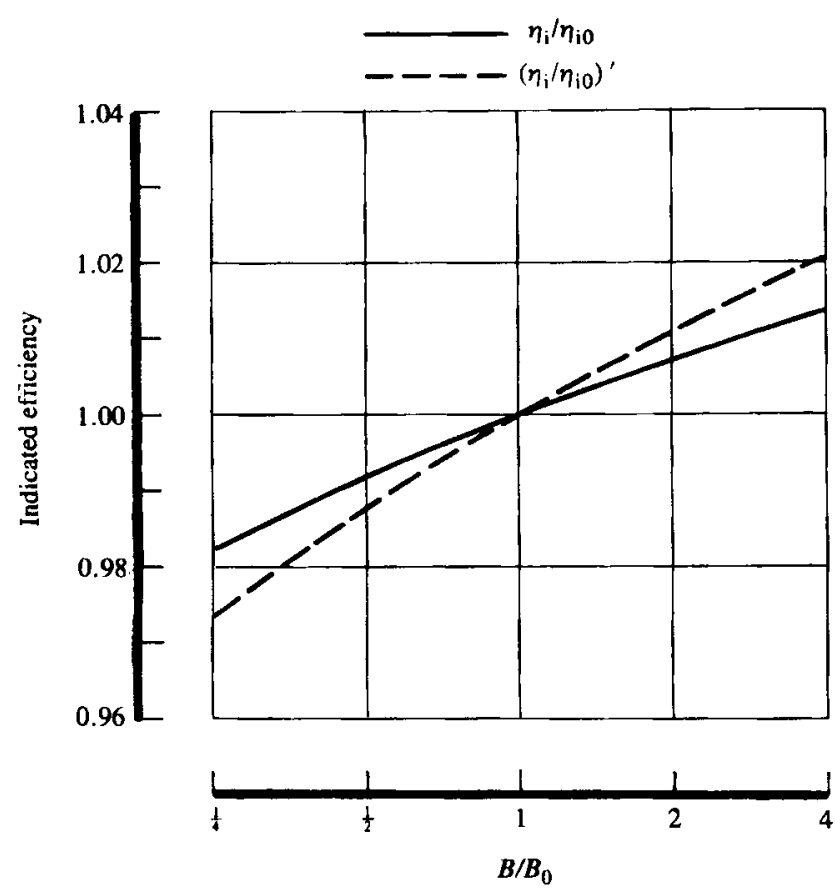

Fig. 3 Influence of engine size on indicated efficiency

mechanical efficiencies for the smaller engines. Other reasons may be lower turbocharger efficiencies or nonsimilarities in the combustion process leading to different rates of heat release.

If even smaller engines are taken into consideration, certain design features such as a smaller air excess ratio may lead to an additional rise in wall heat losses which is not inherently size dependent. Differences in the combustion systems will play an additional role. It can be concluded from these differences in design that the efficiency of small engines could be improved if some of the measures used in large units to achieve high efficiencies were adopted.

\section{CONCLUSIONS}

A similarity consideration of the engine working cycle leads to the finding that the dependence of the wall heat losses on engine size is not due to differences in the surface-volume ratio because this influence is compensated by the engine speed. Instead of this the dependence of the heat-transfer coefficient on the cylinder bore is responsible.

The reason for the size dependence of the heattransfer coefficient has to be looked for in the temperature profile at the cylinder wall. This was shown using Reynolds' analogy.

Using the dependence of the heat-transfer coefficient on engine size it is possible to approximately estimate the dependence of wall heat losses and indicated efficiencies on engine size with simple formulae if similarity is given.

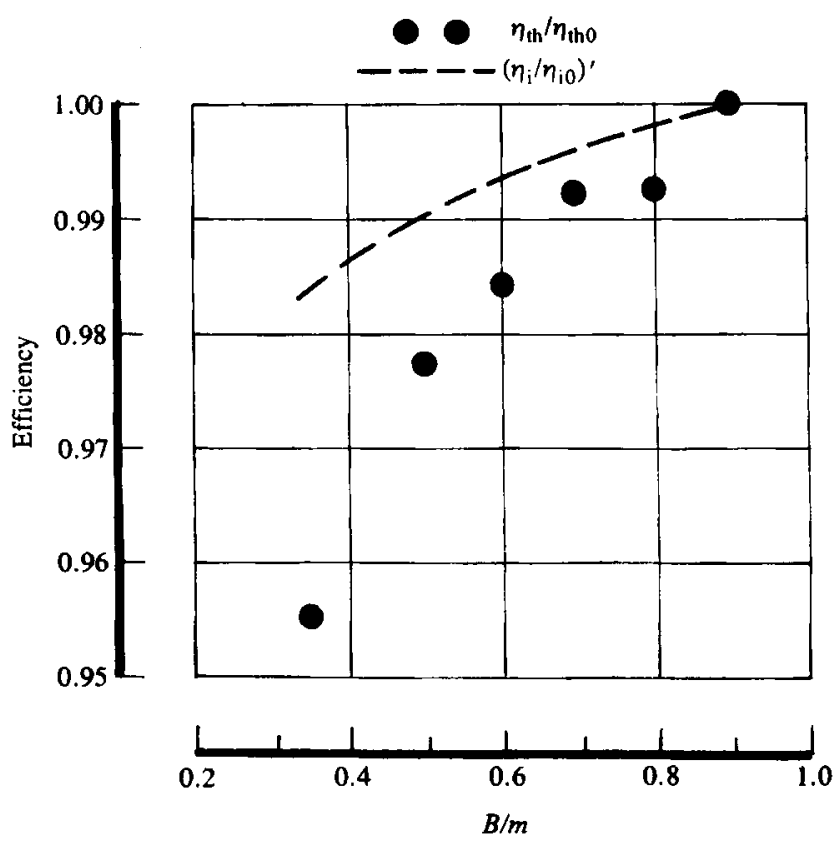

Fig. 4 Influence of engine size on efficiency

The results of the calculations show that only a small part of the considerable differences in the efficiencies of small and large engines is due to size-dependent changes in wall heat losses. Therefore, the remaining differences must result from other effects which, of course, may again be size dependent (for example different combustion systems). Possibly here a potential for higher efficiencies in small engines is available.

\section{ACKNOWLEDGEMENT}

The author wishes to thank Professor Dr-Ing. $K$. Groth, director of the Institut für Kolbenmaschinen, Universität Hannover, for the suggestion to publish this paper.

\section{REFERENCES}

1 Groth, K. Vorlesung Verbrennungskraftmaschinen I, 1981, Institut für Kolbenmaschinen, Universität Hannover, Hannover.

2 Woschni, G. Beitrag zum Problem des Wärmeübergangs im Verbrennungsmotor. $M T Z, 1965,26,4$.

3 Woschni, G. Die Berechnung der Wandverluste und der thermischen Belastung der Bauteile von Dieselmotoren. $M T Z, 1970,31,12$.

4 Gröber, H., Erk, E. and Grigull, U. Die Grundgesetze der Wärmeübertragung, 1955 (Springer-Verlag, Berlin, Göttingen, Heidelberg).

5 Prandtl, L. Führer durch die Strömungslehre, 1965 (Friedr. Vieweg and Sohn, Braunschweig).

6 Vibe, I. I. Brennverlauf und Kreisprozeß von Verbrennungsmotoren, 1970 (VEB Verlag Technik, Berlin).

7 Zapf, H. Untersuchungen zur Vorausberechnung der Ladungsendtemperatur in Viertakt-Dieselmotoren. $M T Z, 1970,31,8$.

8 Mini specification for $L-M C / M C E$, 2nd edition, October 1982 (MAN-B\&W Diesel). 